\title{
Sexual risk among female workers on cruise ships
}

\author{
Michelle Thomas • Michael Bloor • Kirsty Little
}

Received: 4 July 2012 / Accepted: 14 January 2013 /Published online: 25 January 2013

(C) World Maritime University 2013

\begin{abstract}
Data were combined from two studies - qualitative interviews with 19 female cruise-ship workers in a Florida port and 192 quantitative interviews conducted with male and female cruise-ship workers in a European and a Florida port. High rates of partner change were reported in the latter sample: $39 \%$ reported two or more sexual partners in the past year. Logistic regression analysis of 16 different variables showed that gender was the variable most strongly independently associated with a new sexual relationship: women were six times more likely than men to report a new private sexual relationship on their last contract (OR 6.20, $95 \%$ confidence interval 2.01-19.09); $39 \%$ of the female crew reported a new private relationship on their last contract, compared to $16 \%$ of the men. Qualitative data suggest some reasons for this gender imbalance: sexual harassment by male superordinates, the taking of a lover for protection from harassment and the liminal character of shipboard life. Parallels are drawn with other studies depicting risk behaviour as situated actions (i.e. shaped by the material and social circumstances in which the action occurs), and with studies which see women's greater propensity to risk behaviour in some settings as shaped by power relationships.
\end{abstract}

Keywords Sexual risk behaviour - Occupational health and safety - Cruise ship crews . Gender and risk

\section{Introduction}

In the field of occupational health, the shipping industry holds an almost unique position. Seafarers have a higher occupational mortality rate than any other occupation

\footnotetext{
M. Thomas $\cdot$ M. Bloor $(\bowtie)$

Seafarers International Research Centre, Cardiff University, 52 Park Place, Cardiff CF10 3AT, UK e-mail: BloorMJ@cf.ac.uk

K. Little

Public Health Wales, 36 Orchard St, Swansea SA1 5AQ, UK

e-mail: Kirsty.Little@wales.nhs.uk
} 
except fishermen: UK seafarers, for example, have an occupational mortality rate that is twice as high as construction industry workers and eight times as high as workers in manufacturing (Roberts and Williams 2007), and Danish seafarers have an occupational mortality rate 11 times that of workers ashore (Hansen 1996). Seafarer morbidity is also reported to be high for many infectious diseases (Bloor et al. 2000).

The cruise sector is the sector of the shipping industry which has shown the most consistent growth since the mid-1980s. Between 1980 and 2001, the number of cruise ships in the international fleet increased by $153 \%$ to 372 vessels, the total gross tonnage tripled and the number of passengers per annum grew by $700 \%$ to 12 million (Mather 2003). By 2010 the number of passengers had further grown to an estimated 14.3 million (Cruise Lines International Association 2010). The shipping industry, including the cruise industry, is the traditional industry that more than any other has been transformed by globalising economic forces, creating what is effectively a single global labour market for seafarers (Alderton et al. 2004). Wu's (2005) analysis of the cruise sector labour force showed seafarers of 99 different nationalities. In addition to the international mix, the cruise sector is one of the few industries to employ large numbers of residential female workers: female seafarers are predominantly found in the 'hotel' and catering departments. Wu reported that, in $2000,19 \%$ of the cruise labour force were women ( $\mathrm{Wu} 2005$ ).

The issue of sexual risk behaviour among cruise ship workers lies at the nexus of a number of diverse literatures: epidemiological studies of the correlates of partner change, sociological studies of the social contexts of sexual risk behaviour and sociological studies of occupational risk behaviour.

Epidemiological studies of partner change Seafarers are unusual in that they share a living space, as well as a workplace, with their fellow workers. Furthermore, they are physically remote from their partners ashore for months at a time. National sexual surveys have shown that women whose work involves overnight stays away from home report higher numbers of sexual partners (Wellings et al. 1994). Twenty years ago there was evidence of high rates of sexual risk behaviour among seafarers: a review of studies of STDs among seafarers found that the prevalence of gonorrhoea in different national groups of seafarers was between five and 20 times the national prevalence rates for males (Vukansanovic and Low 1991). Expatriate and migrant workers, such as seafarers, have been identified as persons with higher levels of risk of HIV infection (Houweling and Coutinho 1991). Many of the present generation of seafarers are routinely screened for HIV and other sexually transmitted diseases, with the result that labour force surveys understate prevalence because of the extrusion of infected persons from the study population (the so-called healthy worker effectCarpenter 1987). However, screening studies of Vietnamese seafarers between 1998 and 2002 showed HIV prevalence ranging from 2 to $24 \%$ (Ford and Chamratrithirong 2008) and surveys of HIV risk behaviour show high levels of risk behaviour among national seafarer populations from Italy (Grappasonni et al. 2011) to the Kiribat islands (Robate et al. 2010).

Studies of the social contexts of risk behaviour The cruise ship is arguably a 'liminal space' (Turner 1967), where crew are physically and emotionally removed from the ties and constraints of their homes and families. Lamvik (2002) has also drawn 
attention to the liminal character of seafarers' working environment, and liminality has been suggested as a contributory factor in the sexual behaviour of young holidaying Britons - the holiday providing a setting where individuals can temporarily disregard the statuses, responsibilities and patterns of behaviour carried by them, and expected of them, in their lives at home (Thomas 1999, 2005a).

Spaces that are liminal in respect of freedom from the ties of home may also be spaces where individuals find themselves at risk and subject to constraint as a consequence of local strategic relations of power. Prostitution studies (e.g. Bloor et al. 1993; Bloor 1995), for example, have shown how prostitutes' ability to practice safer sex may depend on their successful resistance to client domination in taking control of the sexual encounter. Sexual relationships are also power relationships (Holland et al. 1990; Lear 1997) and gendered power inequalities may be enhanced in isolated workplaces where female workers occupy largely subordinate positions.

Studies of occupational risk behaviour The importance of power relationships is also evident in the literature on occupational risk behaviour. Bellaby's (1999) monograph 'Sick from Work' (following earlier sociological studies of occupational risk behaviour, such as Gouldner 1954 work on gypsum miners, Perrow's (1984) work on 'normal accidents' and Rayner's (1986) work on hospital workers' exposure to radiation hazards) suggested that, while some workers may be incentivised to take risks, many workers have risks thrust upon them. Following Bellaby, we may best describe workers, not as taking risks, but as incurring them. The study of the sexual risk behaviour of a residential workforce may have particular interest insofar as we may discover how far the constraints and power relations of the workplace may help us understand how workers' incur personal (non-occupational) risks.

Health and risk behaviour The literature on health and risk behaviour is enormous (cf. the review by Alasewski and Horlick-Jones 2002). There is a tension between, on the one hand, those (largely psychological) studies which view risk behaviour as arising out of individuals' perceptions, individuals' motivations and individuals' calculations and, on the other hand, those sociological studies which view risk behaviour as being explicable from an understanding of the immediate social situation (with its constraints and opportunities) in which the risk behaviour occurs. Taylor-Gooby has suggested that one possible bridging concept that might link these contrasting approaches is that of 'framing', where it is clear that 'the context in which the risk is perceived and understood exerts a major influence on the way people understand it and how they respond to it' (TaylorGooby 2002, 110). There may therefore be particular interest in a study of risk behaviour in a particular context (cruise ships) that is so sharply physically and socially isolated.

\section{Methods}

The first (qualitative) study of the two reported here was one component of an ILOfunded study of women seafarers across the various sectors of the shipping industry (Belcher et al. 2003). The qualitative study raised concerns about sexual risks to women cruise workers and it was decided to follow up this topic with a larger quantitative study, core-funded by the Seafarers International Research Centre. 
The 19 interviewees in the qualitative study were recruited by the first author in the seafarers' mission at a Florida cruise port at the end of 2001. Missions represent valuable locations for contacting seafarers for research purposes without having to go through the medium of an employer. Female seafarers using the mission facilities were approached by the researcher and asked if they would be willing to take part in a confidential and anonymous in-depth interview. On the advice of the mission port chaplain, all the women who took part in the study were offered a free ten-dollar phone card as compensation for their limited time. The women were all between 24 and 35 years old and were from South America, South East Asia, Australia, Eastern Europe and the USA; all worked in the hotel and catering or entertainment departments. Transcripts of the interviews were analysed systematically using analytic induction (Bloor 1978). More details of the methods are reported in Thomas (2003).

The 192 interviewees in the quantitative study were recruited in the same Florida mission and in a mission at a European cruise port. The European mission had hotel facilities for seafarers to stay overnight at the start of their contracts, prior to joining their vessel, so seafarers there usually had more time to talk than at the Florida mission - this was reflected in their higher response rate (65 versus $40 \%$ ); the overall response rate of $49 \%$ was judged satisfactory for a study using cold-contact recruitment (Thomas et al. 2007). Women were slightly more likely to agree to take part than men (53 versus $48 \%$ ); the most common reason for refusal was lack of time. Again, interviewees were offered ten-dollar phone cards to compensate them for their time.

The interview schedule and procedures were based in part on the UK's National Survey of Sexual Attitudes and Lifestyles, NATSAL (Wellings et al. 1994), with additional questions from a past survey on the sexual risk behaviour of international travellers (Bloor et al. 1998). These past questions have been extensively piloted to ascertain interviewee acceptability, but additional piloting was undertaken for this study with special attention being paid to comprehension. English was the second language of most of the interviewees, but English is the international language of the sea and proficiency in English would have been an employment requirement. Internal consistency of responses (Smith 1975) was high.

No comprehensive census of the global cruise ship workforce is available for comparative purposes, but comparisons can be made with Wu's (2005) study of the cruise ship workforce based on a sample of cruise ship crew-lists (submitted by ships' masters to a sample of port authorities in 2000). The achieved missions sample is very similar to Wu's characterisation of the workforce. Thus, women comprised $18 \%$ of the mission's sample (versus Wu's $19 \%$ ) and the largest national group was that of Filipinos, comprising $31 \%$ of the mission's sample (versus Wu's $29 \%$ ). Recruitment in the missions occurred on a time-sampling basis as an additional guard against recruitment bias.

Backwards stepwise regression (Menard 2002), with an initial 16 variables, was used to model the sexual behaviour of that portion of the sample $(N=148)$ who provided information on the number of private sexual partners during their last 'trip' or contract, and for whom data were available on all other variables used in the analysis. The 16 variables examined were: gender, whether condoms were available on board, whether or not the interviewee belonged to a religion, nationality (grouped), age (grouped), whether or not the interviewee expected/hoped to have new romantic/sexual relationship on their trip, weekly regularity of alcohol 
consumption, the interviewee's position on board, marital status, whether or not the interviewee had used the pill as a contraceptive in the past 2 years, whether or not the interviewee had used condoms in the past 2 years, whether the interviewee had received advice on HIV/AIDS, whether or not the interviewee was worried about STDs/AIDS and length of career at sea. It had originally been intended to include rank as a variable in the analysis, but there were insufficient female workers in superordinate positions to run this variable in the analyses reported here.

The findings from the latter quantitative study were reported at the time (Thomas 2005 b) but not comprehensively, because of staff departures. This paper provides for the first time a fuller statistical analysis and systematic comparisons between the latter quantitative data and the earlier qualitative study.

\section{Findings}

As previously stated, $18 \%$ of the total sample were women, $82 \%$ were men. The age range was 20-61 years (mean age, 33); $38 \%$ of the women were aged 20-25 years, compared to $17 \%$ of the men. Data were also collected on length of career at sea. In respect of marital status, $54 \%$ were married, $33 \%$ were single, $6 \%$ were separate$\mathrm{d} /$ divorced, $5 \%$ were cohabiting and $1 \%$ were widowed; women were more likely to be single, separated or divorced. The largest national groups were Filipinos (31\%), Indians (20\%) and Hondurans (9\%). The largest occupational groups were restaurant stewards $(17 \%)$, bar and restaurant waiters (12\%), 'utility workers', i.e. general labourers within the hotel department of the ship (11\%), cabin stewards (10\%) and marine department (9\%, comprising $7 \%$ ratings and $2 \%$ officers). Those who reported that they belonged to a particular religion comprised $84 \%$ of the sample, of whom $60 \%$ were Roman Catholics, $26 \%$ were other Christians, $7 \%$ were Hindus and $5 \%$ were Muslims.

Numbers of sexual partners over time is a valuable measure of levels of sexual activity and potential exposure to sexually transmitted infections. Including the entire sample, the mean number of sexual partners (both private and commercial) in the previous 12 months was 2.26 (median, 1; range, 0-70); $39 \%$ reported two or more partners in the past year. A regular sexual partner at home was reported by $96 \%$ of the men and $71 \%$ of the women ( $77 \%$ overall) and $18 \%$ of interviewees reported one or more casual partner in their home country in the past 2 years. On their current or most recent 'trip' or contract, $33 \%$ reported a 'new' sexual partner: $13 \%$ had commercial sexual relationships only, $2 \%$ had both private and commercial sexual relationships and $18 \%$ had private (non-commercial) sexual relationships only, predominantly with other crew rather than passengers. Female crew were significantly $(p=<0.01)$ more likely than male crew to report a private relationship on their trip: $39 \%$ of women versus $16 \%$ of men. Since cruise ship operators forbid sexual relationships with passengers, the great majority of these sexual relationships would have been with fellow crew members.

All those who reported having paid for sex in the past 2 years reported that they had used a condom on the last occasion. In respect of private sexual relationships on their current/most recent trip, $41 \%$ reported condom use on every occasion they had sex with their most recent partner, $25 \%$ used condoms on some occasions, $6 \%$ used 
condoms on the first occasion only and $28 \%$ never used condoms with that partner. With their regular partner at home, condom use by interviewees was low, with $62 \%$ never using condoms.

The high level of workplace sexual activity in this sample together with only limited condom use was further investigated by backwards stepwise regression (see Table 1). Table 1 shows the final best-fitted model. The alcohol consumption measures were only of borderline significance, but are retained here for completeness. The goodness of fit measure (pseudo $r^{2}=0.21$ ) is satisfactory for data of this type. Gender is clearly the most important predictor of having a new private sexual relationship on one's last trip (OR 6.20, 95 \% CI 2.01-19.09).

Although most cruise companies report having policies prohibiting sexual harassment, $35 \%$ of the women interviewed in the quantitative study reported being worried about unwanted sexual attention on board ship, and women seafarers in the qualitative interviews would frequently mention harassment or unwanted attention from at least some fellow crew:

1. 'I've only had trouble from just one person on board. [..] He's made comments and I just avoid him, don't even look at him. [...] I think he's Norwegian and he said something to me and I said, "Say it again, I don't understand". He said, "You're menu". I said, "What do you mean, lunch, dinner, a bit of dessert?" And he's gone, "Yum, yum, yum".

2. 'These people are away from home, away from their wives, away from their life, for say 10/12 months, to have the same girls to follow round and gawk at. Some of them drive you nuts.'

3. 'They [male crew] always say "Do you want to go to my cabin?" or they try to push, to be, to have some relationship you know? [...] I get very upset I say "What do you think then, am I a prostitute, thinking I am easy?",

Younger and less experienced women, isolated from their homes, could be vulnerable to persistent attentions:

4. 'I had a roommate that was just every day, "Oh Juan thinks I'm pretty, I wanna go see him later". But what? Juan thinks everyone is pretty'.

5. '[Men] just sit down and talk too much or just come to your cabin, or you know, come to where you are working. There's no way to escape [...]. I do remember

Table 1 Logistic regression model of crew variables associated with reporting a new private sexual relationship on their last trip $(N=148)$

\begin{tabular}{llllll}
\hline & OR & SE & $z$ value & $P>[z]$ & $95 \%$ CI \\
\hline Gender & 6.20 & 3.56 & 3.18 & 0.001 & $2.01-19.09$ \\
Belonging to a religion & 4.16 & 2.66 & 2.23 & 0.026 & $1.19-14.60$ \\
Expecting a new romantic/sexual relationship & 3.49 & 1.67 & 2.62 & 0.009 & $1.37-8.90$ \\
Alcohol consumption 1 & 2.12 & 1.13 & 1.41 & 0.158 & $0.75-6.03$ \\
Alcohol consumption 2 & 3.81 & 2.38 & 2.14 & 0.033 & $1.12-12.99$ \\
Worried about STDs/AIDS & 3.23 & 1.81 & 2.09 & 0.036 & $1.08-9.71$ \\
\hline
\end{tabular}

Pseudo $r^{2}=0.21$ 
when I did join the ship, so I feel for young girls because [...] they don't know how to go about it and they don't know what to say. Some of the fellows don't have tact at all. They just come on way too strong and you see it and "Oh my God!"’

Harassment is particularly difficult to deal with when it emanates from superordinates:

6. 'Before I have, I used to have [sexual harassment] with one supervisor-he was calling my cabin all the time-I said, "oh my goodness, this guy is bothering me all the time". I told my husband-he's my husband now, but you know, like my friend before, you know? He said, "Don't worry, don't worry, I'm gonna talk to him". And after that he say, "No, please, don't call my bisana [fellow national], don't call my bisana please, just leave her alone. You know, and just stop it, stop it."

7. 'He's the one [the Security Officer] who goes round talking about sexual harassment and yet he goes round saying comments about all the ladies'

As the sixth extract implies, although women may be predisposed to take a lover for a range of reasons, such as isolation, protection may also be a motive:

8. 'Somehow having a boyfriend to take care of you, it's different. Cos even for married girls, they find boyfriends on the ship.'

9. '[T]his guy, $[\ldots]$ he was the bar manager, he want, he push me a lot to come to his cabin and he was my boss you know? And he give me a hard time because I didn't want to, to stay with him. And you know I have a one friend [...] and I was almost waiting until he finish because he can come to my cabin with me, you know.'

In this respect, the ship represents a liminal space. Shoreside relationships are not necessarily seen as a constraint on shipboard behaviour, but neither are shipboard relationships seen as carrying shoreside obligations:

10. 'All the men just — all/most are married — and say, "Let's go to someplace, lets go". But no foreplay friend, nothing. And I say, for example, "But you are married. What do you want with me? Why do you say this?" "You are on a ship, anything can happen in ship. Doesn't matter if you are married. Anything is not important". After they finish the contract, "Bye bye, I go to my home". Or if you go to your home, another girl come, they start again."

\section{Discussion}

That $33 \%$ of the sample reported a new sexual partner on their most recent 'trip' or contract suggests a relatively high rate of partner change in this group. In fact, $39 \%$ of our cruise ship crew sample reported two or more sexual partners in the past yeara figure that is more than twice as high as the comparable figure for 18-35-year-olds in the UK NATSAL survey (Wellings et al. 1994). These high rates of partner change were roughly comparable between men and women crew members because male crew reported very high rates of commercial sex: $29 \%$ of male crew reported paying for sex in past 2 years, whereas for comparison in the NATSAL 2000 follow-up survey (Johnson et al. 2001) just $4.3 \%$ of men reported paying for sex in the past 5 years. In all cases, interviewees reported that their last commercial encounter 
involved condom use, indicating limited threat in principle of spread of sexually transmitted diseases, although there remains the risk of condom failure and infections such as herpes where condom use is less protective. Additionally, there was some anecdotal evidence that some male crew were misidentifying commercial sexual encounters in the ports as casual private sexual encounters involving gift-giving and less consistent condom use.

Nevertheless, it is those data on rates of private (i.e. non-commercial) sexual partner change that appear to be most important in terms of sexual risk behaviour, and it is the women crew members who have much the highest rates of change. As already mentioned, the UK NATSAL survey had already identified women workers whose work involves overnight stays away from home as having higher rates of partner change (Wellings et al. 1994). However, our regression model, after controlling for the confounding effects of other variables, shows strikingly that women crew members are six times more likely to report a new private sexual partner on their last trip than male crew members. Condom use during these encounters was also less frequent than for commercial sex, with only $41 \%$ of respondents using a condom on all occasions.

Some reasons for these very striking gender differences in this isolated residential work-force are suggested by the qualitative data. Women, occupying mainly low status positions and outnumbered five-to-one in a hierarchical and geographically and socially isolated workgroup, find themselves the constant object of a male sexual gaze - 'follow(ed) round and gawk(ed) at' [data extract 2]. This attention may be flattering ('Juan thinks I'm pretty' [data extract 4) or intimidating especially when the attention is from a superordinate ('he push me a lot to come to his cabin and he was my boss' [data extract 9]). Women may be drawn to taking a lover for self-protection ('Somehow having a boyfriend to take care of you, it's different [data extract 8]') as well as for an antidote to loneliness, and women may feel insulated from shoreside codes of behaviour by the liminal character of the ship ('Anything can happen in ship' [data extract 10]).

\section{Conclusion}

From a health policy standpoint, it seems clear that cruise ship workers represent a potentially important group in understanding and combating the spread of sexually transmitted infections. Although commercial sexual relationships between seafarers and sex workers appear to involve very high levels of condom use, the private sexual relationships between cruise ship workers drawn from different parts of the world represent a significant potential for disease spread. Rates of partner change are high and levels of condom protection are low. Further, these shipboard sexual relationships are followed, between contracts, by sexual relationships with domestic partners and others in the seafarers' home countries. Travel workers in general, and seafarers in particular (Vukansanovic and Low 1991), have long been acknowledged to be both vulnerable to sexually transmitted infections and to be an important locus of disease spread. Traditionally, this is because travel workers have been seen as linking different sex worker populations in a chain of infection (e.g. Carswell et al.'s 1989 work on the role of long-distance lorry drivers in HIV spread in East Africa), but epidemiological modelling work on HIV spread has simply emphasised the 
importance concurrent partners in epidemic spread (Morris and Kretzchmar 1997). Other things being equal, residential workers and workers whose work requires overnight stays away from home are more likely to have concurrent sexual partners.

In respect of our understanding of risk behaviour, we can see sexual risk behaviour among cruise ship workers as 'situated actions' in the tradition of G.H. Mead and Herbert Bulmer (cf. Suchman 1987), crew-members' sexual risk behaviours are shaped less by abstract perceptions and predilections and more by the immediate material and social circumstances in which the action occurs. This approach seems to fit our data better than psychological theories of risk behaviour, such as the health beliefs model (Rosenstock 1974) or the transtheoretical model of behaviour change (Prochaska et al. 1994), which conceive of risk behaviour as essentially volitional. The 'framing' (Taylor-Gooby 2002) of the sexual risk behaviour of this residential workforce is central to our understanding of it.

An important part of the social framing of sexual risk behaviour among cruise ship workers is the lack of domestic constraints on sexual behaviour, part of the 'liminal' (Turner 1967) character of shipboard life. Not only are female workers relatively free of constraints to take lovers, but male workers are also relatively free of constraints to sexually harass women workers, particularly their subordinates.

Theories of risk behaviour should not be gender blind. Rayner's (1986) study of the management of radiation hazards in hospitals has previously demonstrated how different occupational groups within the same occupational setting may exhibit very different patterns of risk behaviour; this study shows that gender differences in risk behaviour in the same occupational setting may be even more striking. Our findings have resonances with other kinds of risk behaviour where women are disproportionately at risk. For example, equipment sharing among injecting drug users, where women (although a minority of users) are proportionately more likely to share equipment than male users (Bloor et al. 2008) and, when sharing, are usually 'second on the needle' (Bourgois and Moss 2004). Women crew may find themselves engaging in sexual risk behaviour as a result of local, strategic, gendered relations of power (Foucault 1980; Bloor 1995), unable to resist effectively the dominating gaze of male superordinates. The plight of these isolated women is a powerful demonstration of the essentially situated character of risk behaviour.

Acknowledgments The qualitative interview study was supported by the International Labour Office and the quantitative study by core funds from the Seafarers International Research Centre. We thank Maria Jimenez, William McCrea, David Mesenbring and Laurence Moore for their assistance.

\section{References}

Alasewski A, Horlick-Jones T (2002) Risk and health: a review of current research and identification of areas for further research-report to the Economic and Social Research Council and the Medical Research Council. www.kar.kent.ac.uk/8383/1/alasewski_risk_and_health.pdf

Alderton T, Bloor M, Kahveci E, Lane T, Sampson H, Thomas M, Winchester N, Bin W, Zhao M (2004) The Global Seafarer: living and working conditions in a globalized industry. International Labour Office, Geneva

Belcher P, Sampson H, Thomas M et al (2003) Women seafarers: global employment policies and practices. International Labour Office, Geneva 
Bellaby P (1999) Sick from work: the body in employment. Ashgate, Aldershot

Bloor M (1978) On the analysis of observational data: a discussion of the worth and uses of inductive techniques and respondent validation. Sociology 12:545-552

Bloor M (1995) The sociology of HIV transmission. Sage, London

Bloor M, Barnard M, Finlay A, McKeganey N (1993) HIV-related risk practices among Glasgow male prostitutes: reframing concepts of risk behavior. Med Anthropol Q 7:1-19

Bloor M, Thomas M, Hood K, Abeni D, Goujon C, Hausser D, Hubert M, Nieto J-A (1998) Differences in sexual risk behaviour between young men and women travelling abroad from the UK. Lancet 352:1664-1668

Bloor M, Thomas M, Lane T (2000) Health risks in the global shipping industry: an overview. Health, Risk \& Soc 2:329-340

Bloor M, Robertson M, McKeganey N, Neale J (2008) Theorising equipment-sharing in a cohort of Scottish drug users. Health, Risk \& Society. doi:10.1080/13698570802533697

Bourgois P, Moss A (2004) The everyday violence of hepatitis C among young women who inject drugs in San Francisco. Hum Organ 63:253-264

Carpenter L (1987) Some observations on the healthy worker effect. Br J of Ind Med 44:289-291

Carswell J, Lloyd G, Howells J (1989) Prevalence of HIV-1 in East African lorry drivers. AIDS 3:759-761

Cruise Lines International Association. (2010) The state of the cruise industry in 2010. www.cruising.org/ vacation/news/press_releases

Ford K, Chamratrithirong A (2008) Migrant seafarers and HIV risk in Thai communities. AIDS Educ Prev 20:454-463

Foucault, Michel (1980) The eye of power. Michel Foucault: Power/Knowledge, ed Colin Gordon, 54-71. Brighton: Harvester

Gouldner A (1954) Patterns of industrial bureaucracy. Free Press, Glencoe

Grappasonni I, Paci P, Mazzucchi F, Amenta F (2011) Survey on HIV risk perception and sexual behaviours among seafarers. Int $\mathrm{J}$ of Maritime Health 62:131-137

Hansen H (1996) Surveillance of deaths on board Danish merchant ships. 1986-93: implications for prevention. Occup and Environ Med 53:269-275

Holland J, Ramazanoglu C, Scott S (1990) AIDS: from panic stations to power relations-sociological perspectives and problems. Sociology 25:499-518

Houweling H, Coutinho R (1991) Risk of HIV infection among Dutch expatriates in Sub-Saharan Africa. Int J STD AIDS 2:220-230

Johnson A, Catherine Mercer C, Erens B et al (2001) Sexual behaviour in Britain: partnerships, practices and HIV risk behaviours. Lancet 358:1835-1842

Lamvik G (2002) The Filipino seafarer-a life between sacrifice and shopping. PhD thesis. Trondheim: Norwegian University of Science and Technology

Lear D (1997) Sex and sexuality: risks and relationships in the time of AIDS. Sage, London

Mather C (2003) Sweatships: what is it really like to work on cruise ships. War on Want/International Transportworkers Federation, London

Menard S (2002) Applied logistic regression analysis. Sage University Paper 106. Sage, Thousand Oaks

Morris M, Kretzchmar M (1997) Concurrent partnerships and the spread of HIV. AIDS 11:641-648

Perrow C (1984) Normal accidents. Basic Books, New York

Prochaska J, Norcross J, Di Clemente C (1994) Changing for good: the revolutionary programme that explains the six stages of change and teaches you how to free yourself from bad habits. W. Morrow, New York

Rayner S (1986) Management of radiation hazards in hospitals: plural rationalities in a single institution. Soc Stud Sci 16:573-591

Robate M, Toatu T, Kiriton R, Duffy G, Bryar T (2010) Sexual behaviour of Kiribati seafarers: second generation surveillance in 2005 and 2008. Int J of Maritime Health 62:195-200

Roberts S, Williams J (2007) Update on mortality for workers in the UK merchant shipping and fishing sectors: report for the Maritime and Coastguard Agency and the Department of Transport. Southampton: MCA Research Report 578. http://www.mcga.gov.uk/c4mca/rp_578_final_report_revision_22.pdf Accessed 2 February 2011

Rosenstock R (1974) The health beliefs model and preventive health behaviour. Heal Educ Monogr 2:354-386

Smith H (1975) Strategies of research: the methodological imagination. Prentice Hall, Englewood Cliffs

Suchman L (1987) Plans and situated actions: the problem of human/machine communication. Cambridge University Press, Cambridge

Taylor-Gooby P (2002) Editorial: varieties of risk. Health, Risk \& Society 4:109-111

Thomas M (1999) Foreign affaires: a sociological exploration of 'holiday romance'. PhD thesis. Cardiff University

Thomas M (2003) Sexual health of women working aboard cruise ships. Heal Educ J 62:293-303 
Thomas M (2005a) 'What happens in Tenerife stays in Tenerife'-understanding women's sexual behaviour on holiday. Culture Health \& Sexuality 7:571-584

Thomas M (2005b) The sexual health of cruise ship crews. Cardiff University: SIRC. http://www.sirc.cf. ac.uk/pdf/symposium\%20Proceedings\%202005.pdf Accessed 2 February 2011

Thomas M, Bloor M, Frankland J (2007) The processes of sample recruitment: an ethnostatistical perspective. Qual Res 7:429-446

Turner V (1967) The forest of symbols. Cornell University Press, Ithaca

Vukansanovic P, Low A (1991) Venereal diseases among seafarers. Travel Medicine 9:121-123

Wellings K, Field J, Johnson A, Wadsworth J (1994) Sexual behaviour in Britain: the national survey of sexual attitudes and lifestyles. Penguin, Harmondsworth

Wu Bin (2005) The world cruise industry: a profile of the global labour market. Cardiff University: SIRC. http://www.cf.ac.uk/pdf/worldcruiseindustry.pdf Accessed 2 February 2011 